\title{
THE CONSTRUCTION OF SUBJECTIVITY
}

The doctrinal antagonisms that have appeared in the history of philosophy have often been an expression of tensions existing in those very problems that have generated philosophical thinking. I think that the fundamental task of phenomenology must consist in the clarification of those problems, insofar as they are constituted by strictly phenomenal situations that have provided both the riddles provoking philosophical theories as well as the basic materials for their theoretical construction.

It is evident that subjectivity is at the center of most controversies that have stirred modern philosophy, provoking the most diverse theses. On many of those occasions, however, the suggestion of their fundamental motives cannot be denied. Thus, all the suspicion that might have been raised by Descartes' mentalist substantialism does not prevent the unavoidable evidence of his thesis that "this truth: I think, therefore $I \mathrm{am}$,[is] so firm and so assured that the most extravagant suppositions of the skeptics could not shake it." (Discourse on Method, Part IV; AT VI, 32) This does not keep us from also being impressed by Hume's apparently antagonistic assertion that "there is no question in philosophy more abstruse than that concerning identity, and the nature of the uniting principle, which constitutes a person." (A Treatise of Human Nature, Selby-Bigge's edition, p. 189) The synthesis of both quotations could yield the problematic evidence of human subjectivity that is expressed in Decartes' statement. Or rather, it would pose the problematicity of a subject that, however, knows about itself with absolute certainty.

Perhaps this suspicious attitude that I adopt, conscious at the same time that it faces an ineluctable theme, is encouraged by the insistence with which the philosophy of subjectivity has been manifest during the last four hundred years. Although in this century the problems concerning human communication, posed from a semantic, ethical, or sociological perspective, have become specially relevant, one cannot deny the fact that under them lies the problem of the constitution of the subjects that communicate and relate morally or socially to each other. An even admitting that the philosophy of subjectivity has often given 
shelter to a ghostly entity that has disturbed a proper understanding of human communication, it is not possible to drive it away by a simple exorcism that would, in the end, leave unanswered any elementary question about what that subject is, for that question whether one likes it or not, is center stage in any inquiry concerning language, morals, society, or human history. Therefore, it is important to investigate how our subjectivity is constructed so as to be an annoying matter due to both its persistence and its defiance of any satisfactory answer. And we resort to the possibility of a construction of subjectivity because, at this point in the history of the problem, we are not captivated by the hypothesis that we have at our disposal some fortunate procedure that, after the fashion of Descartes' intuition, will make us face, in an immediate and clairvoyant way, that subject that we believe ourselves to be.

As people living at the end of the twentieth century, born and bred with the conviction that language provides the main instrument with which we face things and also ourselves, we can start our reflection by asking what the personal pronouns that account for our own, and other people's, subjectivity mean. To phrase it another way, adopting a terminology that is both Frege's and Husserl's, what is their sense and reference? Or again, widening the inquiry towards a perspective that fits Husserl's phenomenology better, how are their sense and reference fulfilled by some form of intuitive experience that satisfies them or that frustrates their initial pretensions? But, posing the question now in a way that resorts to Austin's "linguistic phenomenology," it is of interest to investigate not only the cognitive demands that bear down on the semantics of those personal pronouns, but also the axiological or evaluative motives that have decided the construction of subjectivity that is expressed by them, and that might have decided their sense.

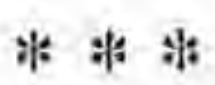

A first approach to the reference and sense of personal pronouns lets us point out that their referential function has special relevance. That is to say, they are basically deictic words, intended to refer to a determined subject, whose determination coincides with that of being the term of the denotation that is made of it. However, it is obvious that the function of "I," "you," "he," or "she" cannot be simply ranked with purely referential elements such as "this" or "that" (not to speak of Russell's "there is one and only one $x$ such that ..."). The reference of 
personal pronouns functions in association with a meaning or sense that cooperates in the determination of what is denoted by them. It is implicit in its use that "I" refers to "the subject that speaking denotes itself," while "you" presupposes "the subject to whom one speaks and is denoted as such," and "he" or "she" mean "the subject of whom one speaks." Therefore, the reference acting in them is directed by a sense, vague and occasional perhaps, that demands the determination of what is referred to as a subject that also takes shape as a participant in a dialogue and is so described in the aforesaid forms of allusion. In regards to what I will discuss further on in this paper, I want to emphasize that, in the determination that is essential to the referential function of personal pronouns, there is an implicit meaningful configuration that directs the denotation towards a determined subject "who speaks," "to whom one speaks," or "of whom one speaks." Therefore, the clarification of what that referential function is, demands, as a previous step, an explanation of what is, at the level of the sense that is proper to personal pronouns, the configuration of the subject alluded to by them. Or, in other words, what is the subjective unity that regulates such determination and that presides over its meaning. And, in order to avoid any misunderstanding, I must warn that with the words "sense" and "meaning" I do not pretend to point at some mysterious entities that we might supposedly have "inside" the mind (if it were legitimate to speak of that "mental inwardness"), but only at the ways in which something is signified; in this case, the subject alluded to by each one of those pronouns. That is, I assume Husserl's theory that sense consists in "the intentional object in the how of its constitution." In the case of personal pronouns, that sense (what in the Logical Investigations was considered to be meaning) is the subject that is objectivized as a participant in a dialogue. As will be shown further on in this paper, it is a very peculiar objectivation, and sometimes it may seem to be paradoxical.

Therefore, taking into account the fact that the reference of personal pronouns is going to be fundamental for the elucidation of the subjectivity denoted or determined by them, its association with the sense that directs it towards some peculiar forms of manifesting that subjectivity forces us to clarify first of all what is essential in its presence. And, in the first place, on a par with the determination of the subject performed by the reference, we have to emphasize the unity that, in any case, presides over its meaning. This is the unity alluded to by Husserl in 
relation to the first person pronoun when he appealed to the "pure I." In the full knowledge that its transference to the second and third person pronouns can introduce serious modifications in Husserl's general theory of subjectivity, mitigating the primacy that he granted to the "I," I think that what is essential in the meaning of the "pure I" can be transferred to the pronouns "you," "he," or "she." That is why I will call it a "pure subjectivity." Applying to it what is essential to Husserl's "pure I," I want to emphasize that subjectivity means, in any case, the unity of consciousness with which any subject is conceived. That is to say, the sense of subjectivity necessarily carries with it the condition of being the unity of conscious activities that, in spite of their diversity, claim the identity of the consciousness that presides over their radiation. Otherwise, the reference of personal pronouns would fail to perform its function of determining a subject; it would dissolve into a multitude of denotations, as many as the moments in which a human activity is present, without being able to constitute the unity of the subject that is to be denoted as "I," "you," "he," or "she."

In order to be fair (perhaps I should now apologize for my propensity to look for antecedents of phenomenology in authors of other times), I think that we should give Kant the credit for having taken the first steps towards that pure subjectivity, leaving the substantialist excesses of Descartes' res cogitans behind. In the Appendices to the "Transcendental Dialectic" in the Critique of Pure Reason (entitled "Of the Regulative Employment of the Ideas of Pure Reason" and "Of the Ultimate End of the Natural Dialectic of Human Reason"), he proposes the idea of mind (das Gemüt) to mean the "hidden identity" that overcomes the diversity of rational activities, the "radical faculty" from which these activities emerge (A 649/B 677), the "systematic unity" of the different faculties (A 650/B 678), or the "personal identity" that persists throughout their changing states, at least in this life (A 672/B 700). Even admitting that the development of Kant's theory of the "regulative employment" of the idea of mind can carry with it some doctrinal elements that do not fit with a phenomenology of subjectivity, it seems legitimate to appropriate his concept of "regulative idea" in relation to the "unity" or "identity" of that transcendental subjectivity. For, posed as a logical demand that is valid a priori for the diversity of the rational activities attributed to a subject, it anticipates Husserl's notion of the pure I (or of pure subjectivity) already advanced in the Logical Investigations (Fifth Investigation, §4) as the "real, 
continuous unity that constitutes itself intentionally in the unity of consciousness." And, further, Husserl says in $\$ \$ 37$ and 122 of Ideas, that from that pure I (or pure subjectivity), the activities of the consciousness unified by it "well" or "radiate." Moreover, stressing its parallel with Kant's idea of mind, Husserl says in $\$ 57$ of Ideas that that subjectivity constitutes a "transcendence in immanence." That is to say, it means an identity that exceeds or transcends the conscious activities whose identity it postulates. It corresponds to the "hidden I" that he refers to in his article "Phenomenology" in the Encyclopaedia Britannica.

In any case, whatever the affinity between Kant's idea of mind and the phenomenological pure subjectivity might be, it is important to emphasize that the heuristic character that Kant attributed to transcendental ideas also predominates in the latter. That is, pure subjectivity is not the object of an intuition facing it as if it were an immediate datum. It is not a part of consciousness as one of the elements composing its real constitution; nor does it mean one of its underlying strata, one that we might infer by means of some reasoning which would bring it to light. It is only a regulative ideal that applies to the activities of consciousness, postulating a unity that can only be found in the assemblage of the conscious acts themselves. As a pure idea or essence, it is only valid as long as it can be verified in the activities that it unifies or identifies as constituents of a determined subject. Therefore, we must investigate how that concrete subjectivity is constructed at the instance of the ideal of unity proposed by pure subjectivity. And to that purpose we have to consider, first of all, how the intentionality of the consciousness that is going to provide the material identified as a particular determined subject conforms with that ideal of subjective identity.

\section{$* * *$}

I am afraid that, from the outset, intentionality seems to be a disturbing element in that process of identification urged by the idea of pure subjectivity. It is clear that intentionality means a primary dispersion or eccentricity of those acts that are to be unified: every conscious act is intentional insofar as it is directed or projected towards an object. That excludes, first of all, this object's being "contained" or enclosed in consciousness (as Brentano claimed when he resuscitated the old concept of intentionality). Far from any relapse into a concealed Cartesianism supposing a mental inwardness (or the corresponding 
outwardness of the things or persons different from the consciousness that thinks of them), intentionality means a fusion of conscious activity with its object. They constitute a single presence, a presence both of the objectivating consciousness and of the object that is made present by it. That is why the intentional object is the "transcendental guiding thread" (transzendentale Leitfaden) that, as Husserl says in $\$ 21$ of his Cartesian Meditations, makes the analysis of any lived experience possible. I can only know something about memory considering the objects remembered; I only know about love and hate, or about any passion and emotion, examining the objects loved and hated, the exciting and moving things that march past the life of a subject. Therefore, intentionality constitutes the presence both of the activity of the subject and of its intentional objects. Or, appealing to Heidegger's disclosedness (Erschlossenheit), intentionality means that human behavior consists essentially in the disclosedness of its world and of the situations in which it projects itself.

It is obviously a question of objects and situations reduced to their strict presence, which by no means eliminates their claim to "reality" when that is at issue. The only thing excluded in the intentional analysis is any supposition about the "absolute reality" that objects might have as things "exterior" to consciousness, or that might be attributed to consciousness as a "thinking thing." Precisely what is excluded by intentionality is any temptation to conceive consciousness as a substance possessing a mental inwardness "within" which representations corresponding to hypothetical "external things" existing in an absolute way "outside" the mind would hover. When we describe a mental act we can by no means confirm that "distinction" with which it was isolated by Descartes from its "external world." The only objects that we know about are those whose presence fuses with the activity that objectivizes them, and that, being its objects, do not appear confined within any private sphere of consciousness as its representations, their authentic reality being beyond that consciousness. Far from consciousness' appearing here as a thing with a privileged substantiality, within which a substitute for real things is created, what predominates in consciousness is the presence of objects, on which it is projected, and only from which can we know something about the consciousness that makes them present. This means that, compared with the protagonism of objects, consciousness is characterized by its evasiveness or evanescence (its elusiveness, as Gilbert Ryle said). That is why Aristotle could 
say that "the soul is in a way all existing things" ( b 21); or, according to Thomas Aquinas' commentary on that passage, "ex obiecto cognoscit homo suam operationem" (De Anima, III ad 4).

It can be easily understood that this connection between consciousness and objects cause these to include not only those that have unequivocal objectivity, that is to say, real objects, but also those that correspond to abstract or ideal beings, and to ficticious, or even contradictory or absurd beings. That is to say, an "intentional object" is everything that can be thought of and expressed in some way, as long as it possesses a configuration that permits it to become present to any conscious activity. Or, as Alexis Meinong claimed, "object" is everything that has a consistence (ein Bestand) that permits it to become the term of a conscious behavior. And, of course, I do not share Russell's view that consistence means "existence" or "reality": it is possessed by real objects, insofar as they have the peculiarity of being such-and-such, as well as by the fictitious "Pegasus," whose lack of existence did not prevent it from being a winged horse. Therefore, objectivity yields to both the whims of fiction and the failures of error: we can objectivize the "geocentrism" of the Ptolemaic system as a configuration of the heavens that we do not share but that was certainly accepted by great numbers of people. In the same way, "black holes" or the "recession of the galaxies" are objective, notwithstanding the problematicity that they might show and that could convert them into new examples of those illusory theories that mark the course of human thought. Therefore, intentional objectivity comprises all that can be configured with a consistence that sets it up against any form of conscious activity, whatever its degree of certainty and evidence or the evaluative modalities with which it is made present. There can be no doubt that Mona Lisa's enigmatic smile has been an object of endless discussion, or that the evaluative character of atonal music has not prevented it from being the object of a whole aesthetic movement, independently of the number of its followers.

Now, in respect to that centrifugal nature of the intentionality of consciousness, it is alarming that it collides with the demand of mental identity or unity that, as we said before, is claimed by the idea of pure subjectivity. If the analysis of lived experiences only shows the manysided balance of their varied objects, it will be hard to maintain the postulate that every human subject is one consciousness that radiates from one center of activity, in which the different perspectives that it 
directs towards the world interweave, and that keeps its identity throughout its various actions in the numerous objective fields in which these are displayed. The identity of the pure subject is in danger of getting lost in an emptiness, or of becoming an arbitrary supposition, if it relies only on the projection of a multiplicity of acts of consciousness on their respective and varied objects. All this could make us suspect that intentionality might be a disturbing element for the interpretation of consciousness. In short, the intentional character of mental acts grants a main role to the intentional object, as a "guiding thread" for the knowledge of lived experiences, since these vanish in deference to the presence of their objects. It could be said that, in accordance with the sense of intentionality, the subject has been dissolved or "deconstructed" (as the "Derrideans" would say), and annulled as the fundamental motive of phenomenology.

However, I think that this pessimistic view can be due to the lure still exerted by the Cartesian assumption that subjectivity must be conceived on the lines of the res cogitans, that, as a well delimited entity, lives in its own reflexivity, enclosed within its self-consciousness and, therefore, differentiated from the "external world," which at most can be "represented" as a problematic entity. But the situation can be less dramatic if we accept the possibility of conceiving subjectivity as the result of a construction that depends not only on intentional objects, but also on the conscious activity that falls upon them. In fact, I have thus far omitted an essential element of intentionality, the mental activity that Brentano referred to when he wrote about the direction (die Richtung) that leads the psychic towards its objects. Husserl granted a much wider development to that dynamism of consciousness when he dealt with the "constituting functions" that organize the objects categorially and that, through judgment, unfold the eidetic network that covers the whole world. It reappears in the pragmatism that predominates in Heidegger's interpretation of "human existence" (Dasein), and in the corporeal dynamism that, in Merleau-Ponty, organizes the structure of the world perceived. Surely, that activity of consciousness suffers from the same evasiveness that has been attributed to consciousness itself, and therefore it is not easy to say much about it beyond its diffusion in the objects that it makes present. However, it is possible to recover that activity up to a point by paying attention to three aspects of its own presence in the constitution of the objects on which it falls.

In the first place, we have to emphasize the intuitive character of the 
initiative with which, despite its evasiveness, any mental act is produced. The decision with which a discursive process is started, with which a judgment is made or a memory is evoked, need not be inferred from any kind of presuppositions. It is immediately lived, the same as the decision (programmed or not) to hit with a hammer or to gesture with a hand. In any case, it is lived as an activity that can have different degrees of tension, from the laxity of rest or waiting to the frenzy of euphoria. And, as such a tension, it can go between different objective situations as the same activity: the initiative that decided the aim of hitting a stone with a hammer fuses without any break in continuity with the activity that raises the hand to hit or with the expectation that the stone will be broken that way. Now, in any of its modalities, that initiative has an entity of its own that is lived as an activity different from the objective situations in which it is projected. That act of hitting the stone with a hammer could be conceived of as an extraneous action, performed by another subject with the same objective constituents and, therefore, lacking the intuition of one's own initiative that, in one's own case, started the whole process or maintained its performance.

Secondly, every subject identifies itself with its activity, since this is the radical condition of every objectivation. That is, this conscious activity is what sets the presence of every subject and, therefore, it appears as the center of the subjectivity that knows itself through that objective presence. Even the assault itself made by the objects perceived, when they impose their real existence on us, counts on the conscious activity that, in the form of expectation, confronts them. Therefore, either as an initiative that generates objectivations or as a passive expectation that assumes them, the initiative is the center of subjectivity before which the whole horizon of the objective extends. But, at the same time, only the activity that animates consciousness avoids its own objectivation in the course of its effective performance. It can objectivize itself as a past or future activity, as well as objectivize the activity of other subjects. But in its own acting, in which it intuits itself flowing in the subject that lives it, it cannot put itself before itself, shaping itself as an objectivity that corresponds only to what, alien to it, becomes its object.

But, in the third place, that intuition of conscious activity, as a condition for every objectivation, submits to the cooperation offered by the objects. That means the fulfillment of the initial thesis that subjectivity is revealed by the objects on which it falls intentionally. But we 
have to take into account that those objects are not a mere product of that activity. They come to meet it and they set their own conditions to which it has to yield or with which it has to cooperate when deriving their objectivation. The initiative that starts the handling of an instrument counts on the possibility, extraneous to that initiative, that that instrument works, that it allows itself to be handled. And the decision to solve a mathematical problem has to adjust itself to the demands set by the very theories that have to come into play in order to obtain the right solution. In this way, taking into account both the activity of the subject and the cooperation given by the objects to different degrees, we can draw a distinction between the objective levels that, by those very degrees of cooperation, bear witness to the consciousness that has contributed to their objectivation. And, without pretending to accomplish any systematic scheme, which would always be arguable in its details due to the influences that interweave among its different levels, we could draw a distinction between the objects that, as classical ideal objects, values, objects remembered, and fictitious objects, offer adequate channels for displaying the activity of consciousness. I want to emphasize the fact that, when speaking of objects that have "a fundamental empirical component," I wanted to avoid the temptation to speak of pure empirical objects that, like the sense data of classical empiricism, could be given in all purity, free from any theoretical or axiological contamination. After the criticism that the interpretation has received from authors such as Merleau-Ponty or Austin, it is only possible to speak of the empirical as a "component," penetrated by objective structures constituted by the activity of consciousness operating with ideas and values, at the behest of theoretical or practical interests. But the acknowledgement of the intimate fusion of what is sensible and what is categorially or axiologically constituted does not prevent us from attributing to the empirical component a decisive function in the alterity of the object. That is to say, an object, insofar as it is constituted empirically, has a component that assails and surprises conscious activity or that, at least, imposes certain qualitative structures that count as the fundamental objective element, that is, as the manifestation of objectivity in its most radical form, meaning the other, what is alien and opposed to the mental initiative that makes it present to consciousness.

Therefore, appealing to other forms of objectivity that appear to be more favorable soil for the initiative of conscious activity, I by no 


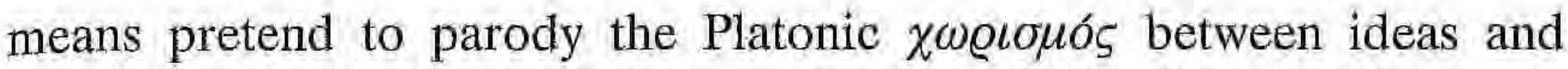
sensible realities. I just want to mention the fact, which is obvious in any case, that the objective structures that can be "idealized" because they register either formal or material essences, are the field in which theoretical activity spreads itself at its ease. This is the field of the "dialectical gymnastics" proposed by Plato in the Parmenides, or that Aristotle conceived as a product of the activity (the $\pi$ in $\eta \sigma \zeta$ ) of the intellect; for, whatever the transcendental strictness of the laws that govern the sphere of ideas, it is always possible to attempt their mutual linking in different ways, until building the huge constructions of scientific theory. And, in any case, they depend on the decision that projects them onto the empirical framework that they must cover. Among those ideas we have to distinguish those that, according to Ortega y Gasset, are the beliefs that function as the living musculature of thought. That is, they are the living foundation that supports every conviction and the general dynamics of our theoretical and practical behavior.

The relation existing between the values and the objective situations axiologically constituted and the activity of consciousness is even more obvious. Their objectivity is backed by the demands that they impose on our behavior and that take the form of systems of practical laws that we face in our volitional or passionate behavior. However, the objective consistence of values makes sense only insofar far as they are the motives that guide or direct any practical purpose or intention. Memories also belong to the sphere of those objectivities that are closest to conscious activity, not only because they are "supported" by the pure exercise of remembering, but also because, as Hume acutely pointed out, they provide the contents with which to construct the identity of the subject going backwards from the present to its previous stages. Finally, it seems idle to point to the world of imagination as the objective field that is most docile to the activity of consciousness. If there are laws that govern it, as could be the case with artistic rules, it seems evident that this is a lawfulness subordinated to the creativity embodied in the work of art and, therefore, to the initiative that gives it existence.

However, all this does not complete the trivial inventory of the objectivities that constitute the field in which conscious activity manifests itself with priority. We still have to include one's own body, whose objectivity is not annulled by the peculiarities of its sensible properties, 
nor by its close fusion with the life of the subject that it manifests. It is true that only the living body has cenesthesic and kinesthesic qualities, that only in it are pain or pleasure, endeavor or fatigue, vividly given. But these are qualities that fuse with no break in continuity with the objectivity of that same body perceived from outside as any other material thing. The impact of a stomachache has the same objectivity as that of a light that comes to us from our physical environment. And the very fingers that I objectively see extended on my hand are the same ones that are affected by a hard blow. But to the exceptionality of the cenesthesic and kinesthesic qualities we must add the quality confered on the body by the fact of its being the primary performer of conscious activity itself in any of its forms. That is, the body is not only the executor of the purposes that are materialized in a behavior exteriorized by its physical performance, but also the fundamental means of exercising higher level activities. It is difficult to conceive the rational and volitional processes without the expressive mechanisms provided by language or by some form of symbols. Words, which are bodily mechanisms, are at least the essential vehicle for performing the activities of thinking and willing. But, on the other hand, the body supplies the channels for the fulfillment of the objectivities proposed by ideas and volitions, since with the body the empirical reality in which that fullfillment must take place is made present. It is the activity that operates through the perceiving body that deploys the objective situations in which volitional projects or theoretical foresight are carried out. Or, considered inversely, the same activity that flows in the corporeity that discovers the empirical world is that which starts and feeds the rational processes that constitute the rational and axiological objectivity that is the field of our theoretical knowledge or of our volitional consciousness. It seems unnecessary to remember at this point the enormous debt that philosophy owes to Merleau-Ponty, whose analysis of corporeity and its perceiving dynamism paid due attention to a topic surprisingly neglected by the philosophy of other times.

Now, what I wanted to point out with this trivial survey of objective fields intimately bound to the activity of consciousness is that they constitute a nucleus of subjectivity. I want to make it clear that I am not resuscitating here any substantialist interpretation of mind. The nuclear subjectivity thus suggested is fundamentally constituted by objective elements and by an activity or initiative that falls upon them giving them life and that cannot be understood as a mental substance which is 
enclosed within itself or which draws around those fields in which it is active a border that turns them into the mere contents of consciousness. On the contrary, what still predominates in this conception is the radical intentionality of conscious activity, that is, the evasiveness or evanescence that derives from its radical projection on the objective spheres that it makes present at the same time that it intuits itself as the dynamic center of that objective presence.

But I also want to point out that with all this we find a second level of intentionality, or, in other words, an intentionality derived from that which has been considered up to now to be the projection of conscious activity on its objects; for the objective levels that compose that nucleus of subjectivity, formed by ideas, values, memories, fantasies, and the body, are also guided or directed towards those that, in the empirical world, fulfill them. An idea or a value lacks sense if it is not projected intentionally on the realities that satisfy its demands. Memories are also fulfilled by the present situations that mesh with what is remembered and justify it. Fictions, whatever their distance from reality, maintain an essential linkage with it, since it is from reality that their constituting elements derive, creating at the same time a world different from the one that we conceive of as being real.

But, at this second level of intentionality, the living body takes on a special importance: it functions as the intermediate link between the nucleus of subjectivity formed by ideas, values, and memories, and the empirical things that fulfill them. Without the bodily activity that moves perception, ideas or beliefs would not have the experiences that could satisfy them, nor would purposes, with their axiological bearing, achieve their aims. Thus, the living body, the body that perceives, that handles and has "at hand" the things that it observes and deals with, plays a decisive role in the nucleus of subjectivity: the channels that constitute the derived intentionality, that is, the lines of fulfillment that go from ideas, beliefs, and axiological purposes to the reality that fulfills them intentionally, pass through the body.

In summary, what I want to suggest with this analysis of intentionality is that an interpretation of subjectivity must take into account above all the projection of conscious activity onto its objects and more, that two levels of objectivity result from this fusion of consciousness with its objects: the level that serves as the nucleus of subjectivity, because it is sustained and enlivened by the initiative of the consciousness that moves and organizes it, and the level of empirical reality that 
in some way surprises or assaults that initiative, that is, imposes on it some objective structures that to a great extent escape from its constituting efficacy. But there is a derived intentionality functioning between both levels, since the first one, the nucleus of subjectivity formed by ideas and values, only makes sense insofar as it is fulfilled in the sphere of experience that at the same time stimulates and generates it, providing the fundamental guidelines for its constitution. The subjectivity that radiates from conscious activity, astride that fulfillment, extends over the world lived by each individual; when dealing with Julius Caesar, for example, his subjectivity does not only embrace the political ideas, the aims, and the values that, as the nucleus of subjectivity, form the central objective field that characterized him, but also the republican Rome in which he lived, the Gaul, the Egypt of Cleopatra, and the Hispania of the Pompeians in which his life transpired. The coordination among these different scenes of his world completes the subjectivity that had its fundamental motive in his initiative and that constitutes the empirical correlate of the idea of pure subjectivity that, as we saw in the beginning, presides over the whole problem.

\section{*** * *}

Now we can return to the question with which we started these reflections: what is the sense and reference of personal pronouns? And, admitting that their sense proposes, in accordance with their reference, the determination of one subject, is it possible to fix the determination of one subject, is it possible to fix the determination of its subjectivity in such a way that it could be the term of the reference that points at it in its individual concretion? All this depends on the fact that subjectivity could be referred to in such a way as to satisfy the denotative function of those terms that seem destined to refer to subjects that, because they are determined, must be marked out from everything that is not their individual entity.

But, if we can trust the considerations that I have made up to now, I am afraid that it is necessary to recognize that personal pronouns lack authentic reference. We will have to admit that "I," far from being the proper noun par excellence in Russell's sense (as Arthur Prior thought, in believing that it refers unequivocally to the subject that utters it) suffers from an alarming vagueness in its referential functioning. As with the other personal pronouns, it cannot be used to denote a strictly 
determined subject, because its sense manifests a subjectivity that in no way differs, with clear limits, from what is not its own entity. On the contrary, subjectivity appears to be something evasive and fluid, projected intentionally on its world and extended over it by intentional channels that make it reach the furthest star and the most remote event. That ambiguity of its indeterminate being prevents us from using in connection with it a philosophical term such as "reference" (the Bedeutung or Beziehung of Kant, Frege, or Husserl) which has been used to allude to the efficacy of expressions as signs of determined objects or states of affairs.

But neither can the difficulty be overcome by appealing to that nucleus of subjectivity formed by the living body and the language that expresses the interests, beliefs, and preferences assumed by a subject and that, as has been suggested, could be the center from which its conscious activity radiates towards those areas of its world that fulfill its intentions. The intentional character that, at the second of the levels that we considered, enlivens that nucleus of subjectivity also projects it on the objects that fulfill it or that form the horizon of its intentions. Although it functions as a privileged seat of the primary intentionality of consciousness, that nucleus of subjectivity is in no way a determined entity, sufficiently marked out from what fills its world. The living body becomes inserted in what is handled and perceived, fuses its active presence with that of the things that it touches and perceives. Just as a word, that extends it meaningfully, becomes encrusted in the ideas and beliefs, in the values that are expressed by it, the body becomes encrusted in the things spoken, and, as Austin would say, performs them as facts of the world spoken of. Thus, there is no border separating the activity of the subject or its basic field of action (the nucleus of subjectivity) from all the other, from all that, as something distinct, could shape it as a determined being, enclosed within the limits drawn by that supposed distinction. Therefore, if we assume that the reference must fall on objects delimited in their own entity, as genuine terms of a denotation, we will have to admit that this does not fit with the use of personal pronouns. The subject extends itself to the limits of its world, even if in a progressive way, proceeding from the nucleus of subjectivity from which radiates the conscious activity with which it originally identifies itself. That is why Ortega y Gasset, in his article "The Two Great Metaphors," said that "man begins to know himself by means of the things that belong to him." The possessive pronoun pre- 
cedes the personal pronoun. The idea of 'mine' is previous to that of ' $I$.'" That is, there is nothing that is properly an $I$ different from mine. "Mine" can be said about everything: the things that make up $m y$ world, my activity itself, that which, as conscious activity, was the center of radiation of subjectivity. Thus, there is nothing that is exclusively an $I$ different from mine, that is, different from the objects that, by being the intentional field in which my conscious activity projects itself, are mine. In any case, we could say of that conscious activity that it is what I have which is most mine, superlatively mine, because it is the center from which the subjectivity that fuses with its world radiates; or yours, or his, or hers, in the case of activity that allows me to identify the subject that I call "you," "he," or "she" (also projected in their world, of course).

I am not suggesting that personal pronouns are idle or lack any legitimate use. Resorting now to formulae from Wittgenstein's Tractatus, it can be said that with them subjectivity shows itself (zeigt, aufweist sich) as an activity that projects itself and evanesces on all the objects of its world, assuming them and integrating them intentionally in the same subjectivity. I would dare to say, therefore, that they are demonstrative terms. Far from being a reference that points to a determined object, the personal pronoun shows an activity that fuses with the intentional objects in which it makes itself present, at the same time that it makes them present as a field of its exercise. The demonstration granted to personal pronouns is, therefore, compatible with the evasiveness or evanescence of subjectivity, that, astride the intentionality of mental acts, evanesces through all that forms its world. But this does not contradict the fact that their sense includes the pure subjectivity (studied by Husserl as the "pure I") which means a strict identity. For, as we have already considered, that identity does not pretend to find a strict fulfillment in a concrete subjectivity that would distinguish itself from everything that is not its individuality. Pure subjectivity was only a heuristic ideal, that is, the program of an identification that must count on the coordination or congruence of the situations that fill a biography. The identity proposed by pure subjectivity can only be fulfilled, therefore, by the diversity of the situations that correspond intentionally to the conscious activities of a subject and that, without giving up their diversity, form a coherent totality inasmuch as its objective elements are bound by intentional links that direct the activity of the subject or are drawn by its very initiative.

Nevertheless, I think that there is something more in that ideal of 
pure subjectivity. It is something to be discovered from a practical or axiological perspective that would broaden what has been considered up to now. And that is this: subjectivity does not constitute itself only in relation to cognitive activities, which are those that have dominated our study. But, without pretending to enter into a discussion about their possible priority, it must be admitted that the forms of behavior determined by practical motives have, at least, a marked relevance in the whole of human activities. In fact, in agreement with our previous review of the constitution of subjectivity, they are found in what we have called its nucleus, that is, those activities and objective situations with which a subject primarily identifies itself. Now then, that gives a special axiological twist to both the ideal of subjectivity that presides over the construction of subjectivity as well as to the activity that impels it. That is to say, pure subjectivity cannot consist simply in the idea of the identity of pure consciousness that makes every objectivation possible, nor is the activity or initiative that impels consciousness ruled by a mere cognitive interest. The axiological character that prevails in at least a good part of conscious processes, if not in all, reverts to them. This means that the construction of subjectivity that I have outlined is made at the instance of an evaluation by the subject as a free being responsible for its acts, which projects them into its world performing some tasks the merit of which must have a decisive bearing on its totality as a human subject. And, therefore, the axiological ideal of a subjectivity that pretends to reach the dignity of a free being, responsible for its destiny, has a decisive bearing on the ideal of pure subjectivity that dominates the whole construction of that subject. The construction of subjectivity, then, is not a purely theoretical matter, but also, in the most radical sense of the world, a dramatic one.

University of Valencia 